\title{
Process Optimization of Steering Axle with Technology of Iron Mold Coated Sand Based on Numerical Simulation
}

\author{
Guangquan $\mathrm{Ku}^{1, \mathrm{a}}$, Yong $\mathrm{Su}^{1, \mathrm{~b}}$, Huihui Zhang ${ }^{1, \mathrm{c}}$ and Naixiong $\mathrm{Xue}^{1}$ \\ ${ }^{1}$ School of Materials Science and Engineering, Hefei University of Technology, Hefei, Anhui, 230009, \\ China \\ akgq19900615qq@163.com, bsuyong1963@126.com, 'zhanghui910921@163.com
}

\begin{abstract}
Keywords: Iron mold coated Sand, Balanced solidification principle, Meanwhile solidification, Graphitizing expansion, Self-feeding.
\end{abstract}

\begin{abstract}
This paper uses the casting simulation software ProCAST to simulate the production of steering axle with technology of iron mold coated sand, and corrects the corresponding process by the simulation results. Utilizing the balanced solidification principle, by increasing the number of the ingates and changing the shape and dimensions of the ingates, the ingates are smooth flow and play a feeding role in the overall contraction of the casting. At the time of overall expansion of castings, ingates are timely closure to facilitate self-feeding. Changing the thickness of sand at different parts of casting, gradually increasing the sand thickness from top to bottom of casting, thinning the sand thickness of hot spot, which can make the solidified process meets the principle of meanwhile solidification. Furthermore the graphitizing expansion can reduce shrinkage defects in castings.
\end{abstract}

\section{Introduction}

Steering axle usually assumes task of steering. It uses the knuckle in the axles to make the both wheels deflect a certain angle to achieve mechanical steering. Because it plays the role of mechanical steering, there is a very high demand for its performance.

By uniformly covering a layer of 5-8mm thermal solidified sand in the iron mold cavity, a special foundry called iron mold coated sand is obtained. Stiffness mold helps make full use of graphitizing expansion of cast iron, and further reduce the shrinkage defects in casting. The iron casting has a fast cooling rate which effectively refines the microstructure and strengthens the mechanical properties. Moreover, the technology needs less sand and saving cost. has good surface quality which can greatly reduce post-machining time, and can achieve a small riser or no riser as well as high production rate.

\section{The establishment of a solid model}

Structural feature of steering axle. Three-dimensional modeling diagram of a common mechanical steering axel as Fig. 1. Its exterior size is $784 \mathrm{~mm} \times 324 \mathrm{~mm} \times 164 \mathrm{~mm}$. the overall thickness is relatively uniform. The wall thickness of both sides is $12 \mathrm{~mm}$, and the upper and lower is $16 \mathrm{~mm}$. There are two heavy cylindrical parts $(\mathrm{d}=55 \mathrm{~m})$ at upper and lower parts of casting, where is likely to appear Shrinkage defects. Furthermore the structure span of casting is large and narrow, but the wall's thickness does not change significantly. Locality exist final solidification region namely hot spot. 


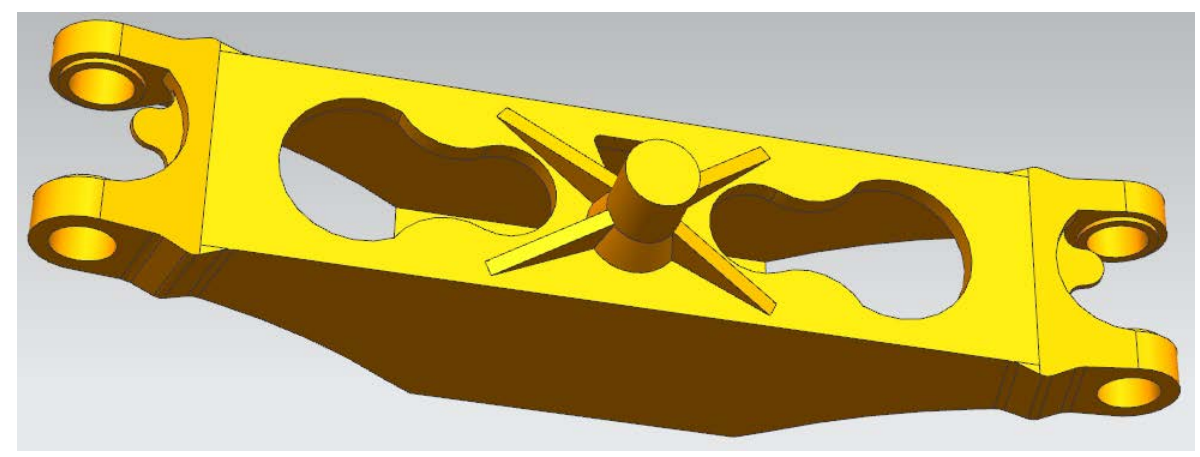

Fig. 1 Model of mechanical steering axle

Brief introduction of Iron mold coated Sand. By uniformly covering a layer of 5-8mm thermal solidified sand in the iron mold cavity, a special foundry called iron mold coated sand is obtained. Because of stiffness mold and thick sand layer, casting is cooled quickly, granularity of sand is small, so the dimensional accuracy v compactness s surface quality the degree of grain refinement and rate of spherify of casting can be significantly improved [1]. Process schematic of Iron mold coated sand is shown in Fig. 2.

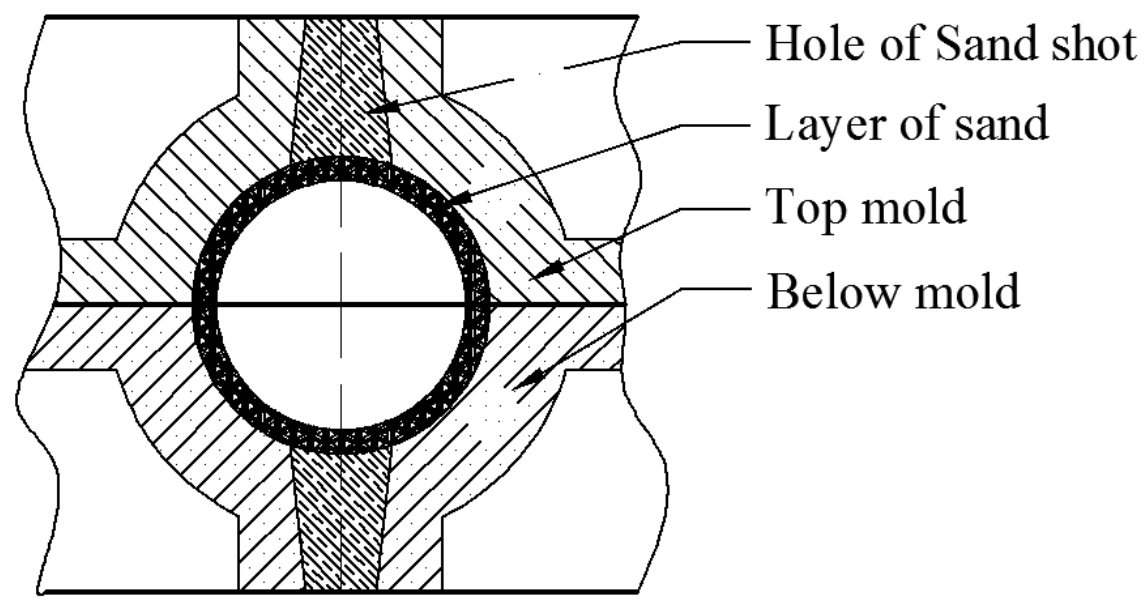

Fig. 2 Process schematic of Iron mold coated Sand

\section{Process formulation and simulation result}

Original process. In order to improve process yield and reduce post-processing difficulty, a foundry method with non-riser is used. According to Osann laws [2]to calculate the size of downsprue 、cross gate and ingate. And the cross-sectional views are shown in Fig. 3. Sand thickness is $8 \mathrm{~mm}$. Two products are produced in a box every time. Taking modeling convenience into account, mold joint is created in below surface of upper wall , two ingates are set on per casting. Pouring temperature is about $1360{ }^{\circ} \mathrm{C}$, pouring time is about 28 seconds. Parameter of this kind ductile iron is shown in Table 1.

The simulation results of the original process. Ductile iron has good Casting performance, the defect is prone to be shrinkage, and such kind of defects has a great impact on the quality of the casting, so requiring strict control. Fig. 4 is the shrinkage distribution based on original process. This figure shows that there are a large number of Shrinkage defects on casting. Total possible shrinkage volume measured by software is about $372.24 \mathrm{~cm}^{3}$, the actual shrinkage volume is about $16.55 \mathrm{~cm}^{3}$, the rate of actual shrinkage is $4.45 \%$, and the maximum possible rate of shrinkage is 83.5\%, it means here is prone to defects' appearance.

Process improvement and simulation result. Because of the no-riser foundry, there will be a lot of shrinkage defect when the process is improper. So a balanced solidification principle [3]is used to design the ingates to play a feeding role .At the same time make use of ductile iron's 
graphitizing expansion as much as possible to reduce the tendency of shrinkage defects Fig. 5 [4] is the Superposition of contraction and expansion of iron castings.

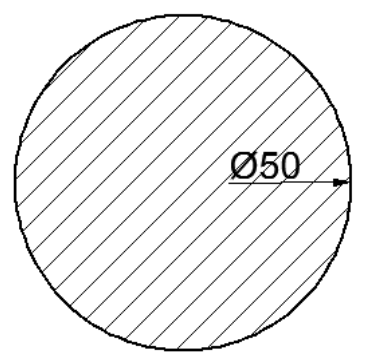

(a)

Downsprue

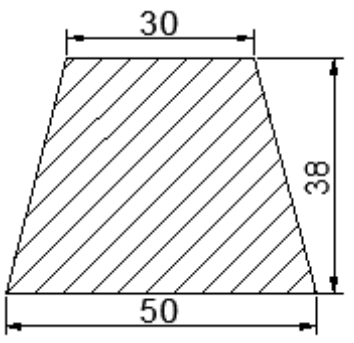

(b) Cross gate

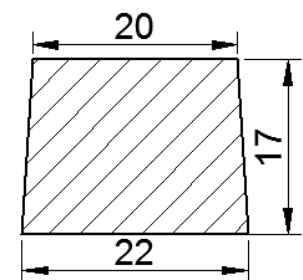

(c) Ingate

Fig. 3 Sectional shape of each runner

Table 1 Thermal parameters of this kind of ductile iron (near $1300^{\circ} \mathrm{C}$ )

\begin{tabular}{ccccc}
\hline $\begin{array}{c}\text { Density } \\
\mathrm{g} / \mathrm{cm} 3\end{array}$ & $\begin{array}{c}\text { Liquids } \\
\text { temperature } /{ }^{\circ} \mathrm{C}\end{array}$ & $\begin{array}{c}\text { Solidus } \\
\text { temperature } /{ }^{\circ} \mathrm{C}\end{array}$ & $\begin{array}{c}\text { Specific heat } \\
\mathrm{J} /\left(\mathrm{g} \bullet{ }^{\circ} \mathrm{C}\right)\end{array}$ & $\left.\begin{array}{c}\text { Thermal } \\
\text { conductivity } \\
\mathrm{W} /(\mathrm{cm} .\end{array}{ }^{\circ} \mathrm{C}\right)$ \\
\hline 6.4 & 1176 & 1167 & 0.86 & 0.23 \\
\hline
\end{tabular}
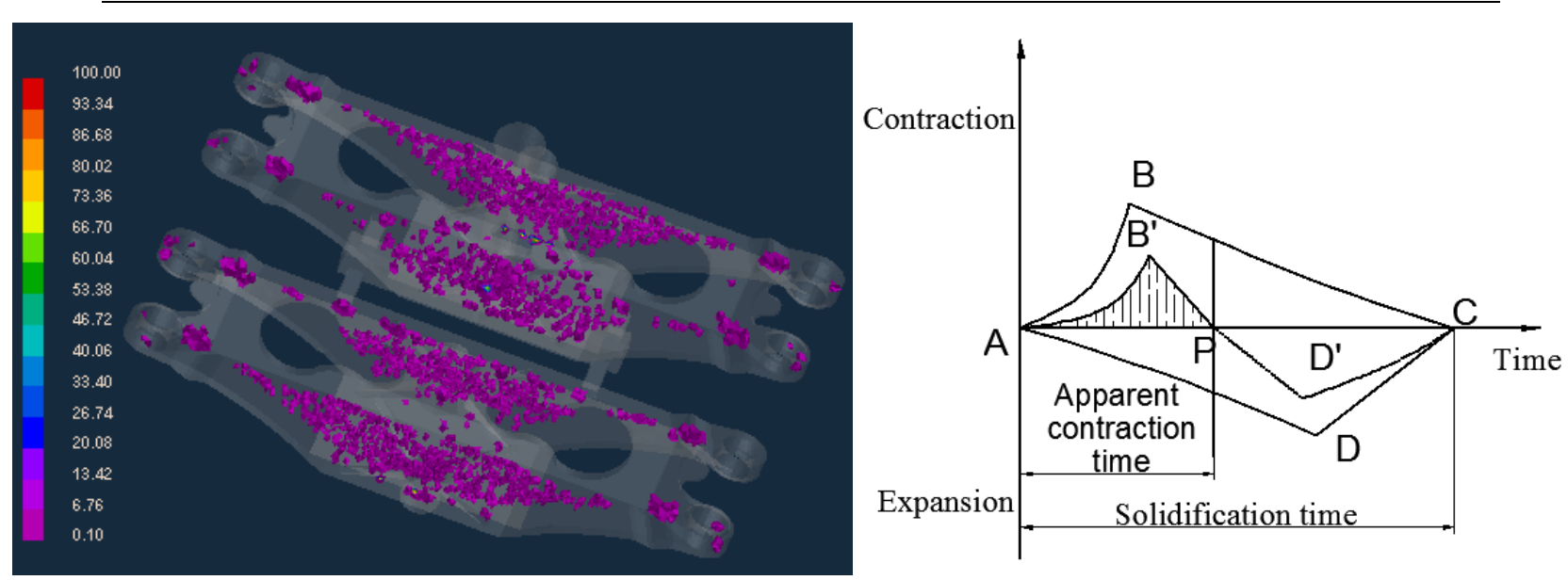

Fig. 4 Shrinkage schematic diagram of simulation results based on original process (left)

Fig. 5 Superposition of contraction and expansion of iron castings (right)

This figure shows that AC period is the solidification process. During AP period the casting is contracting, castings require feeding from external riser or runners. PC period is the process of expansion, to avoid backflow of iron liquid caused by graphitizing expansion which can cause shrinkage defects, the ingates should be completely closed. So ingates completely or mostly solidified at time $\mathrm{P}$ is very reasonable. Based on this principle, the number of ingates of per casting is increased to four, and adds a riser at every outer ingate and cross runner to make sure there is enough iron liquid and high temperature in outer ingate to feed the casting. Then bend-shaped ingates with same cross-section are made to plug itself when the casting is expanding. Three views of ingate cross-sectional view of ingate and riser are shown in Fig. 6. 

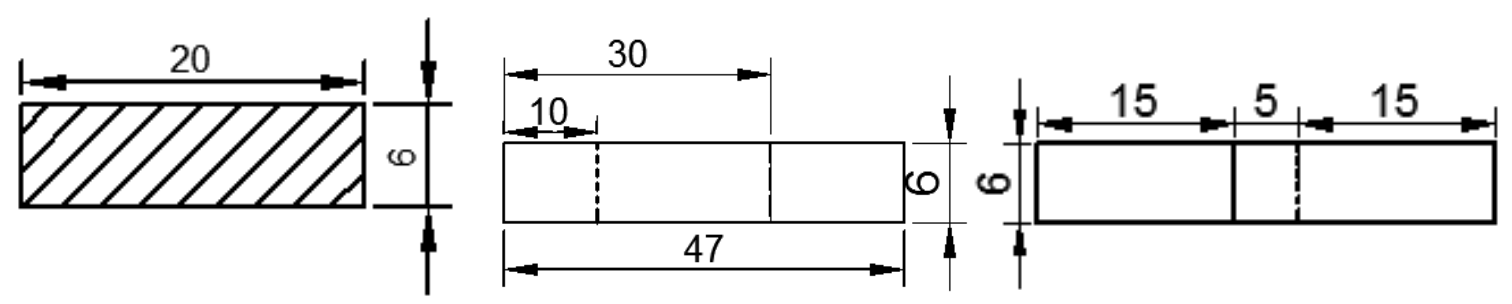

$\begin{array}{lll}\text { (a) Cross-sectional view of ingate (b) Left view of ingate } & \text { (c) Front view of ingate }\end{array}$
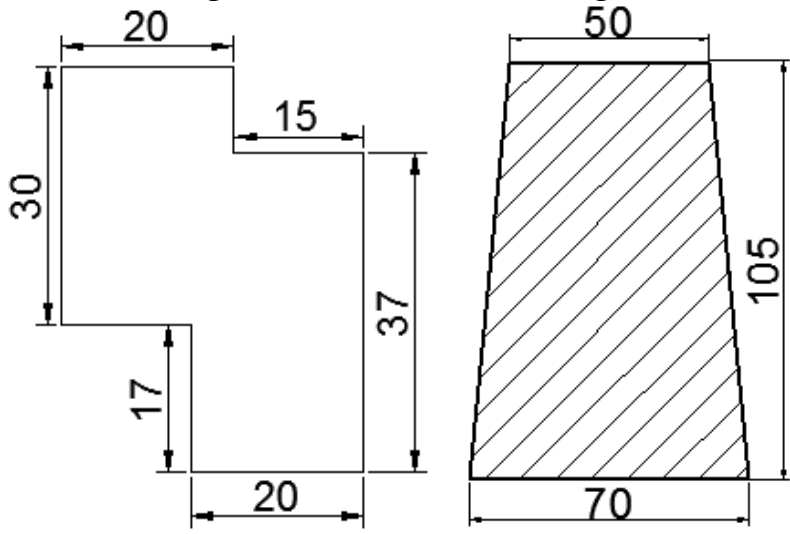

(d) Top view of ingate

(e) Cross-sectional view of riser

Fig. 6 Shape of ingate and riser of new process

The simulation result of improved process is shown in Fig. 7. According to the simulation results, we can know that the number of shrinkage defects decreased obviously. But the shrinkage is still widely distributed. Total possible shrinkage volume measured by software is about $349.39 \mathrm{~cm}^{3}$, the actual shrinkage volume is about $5.01 \mathrm{~cm}^{3}$, the rate of actual shrinkage is $1.43 \%$, and the maximum possible rate of shrinkage is $56.1 \%$. It shows the tendency of shrinkage has reduced, and process improvement has played a positive role.

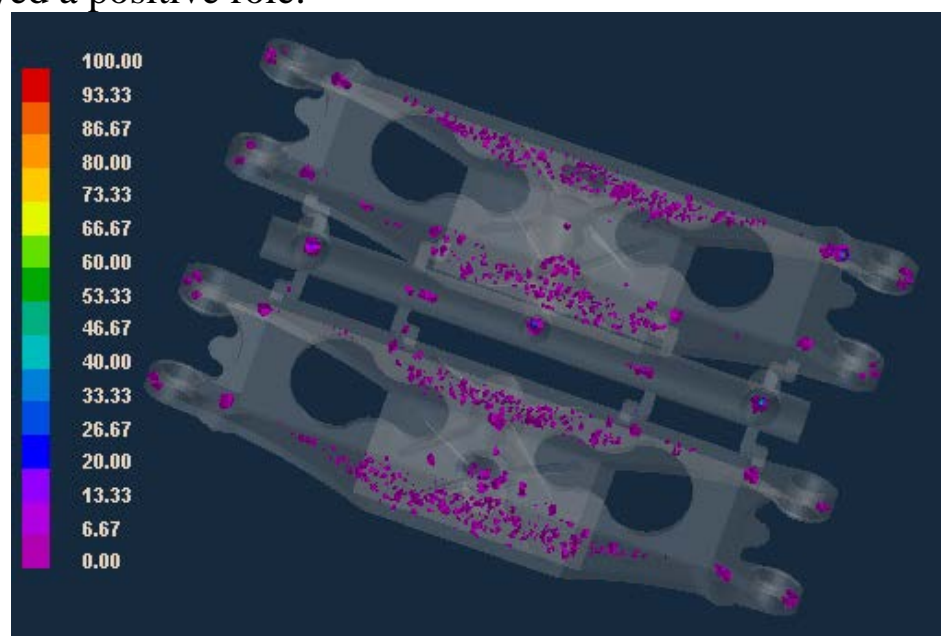

Fig. 7 The simulation result of new process

Further process optimization and simulation result. Although the number of defects is significant reduced by new process, there are still obvious local Shrinkages, so further improvement is needed. We can know that if the solidification process meets the principle of meanwhile solidification, more perfect casting can be gotten theoretically. For this reason the thickness of sand layer will be changed. 


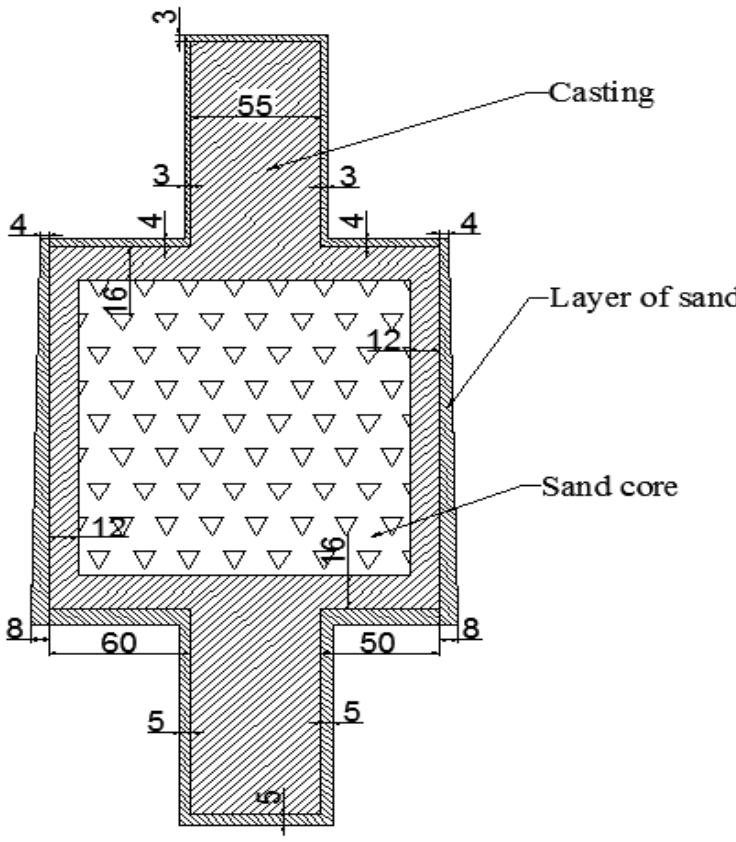

Fig. 8 Intermediate sectional view

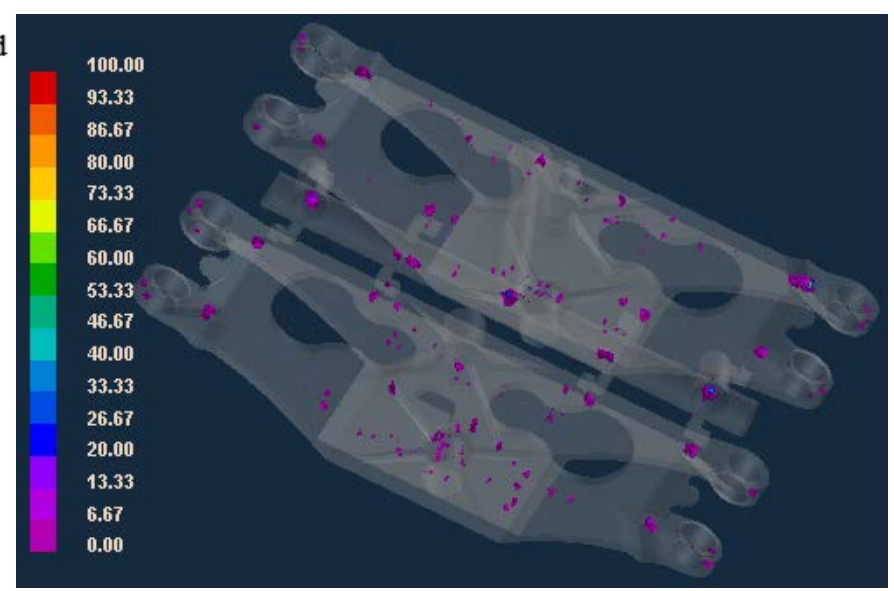

Fig. 9 Simulation result of optimization process

The sand thickness gradually increases from top to bottom of the casting. So temperature of iron liquid first flowing into the mold is lower, but its cooling rate is slow; temperature of iron liquid later flowing into the mold is high, but its cooling rate is fast. Thinning the sand thickness of hot spot can make the iron liquid curd almost at same time [5]. The original thickness of sand is $8 \mathrm{~mm}$ at anywhere. The distribution of sand thickness after process improvement is shown in Fig. 8. It shows intermediate sectional views.

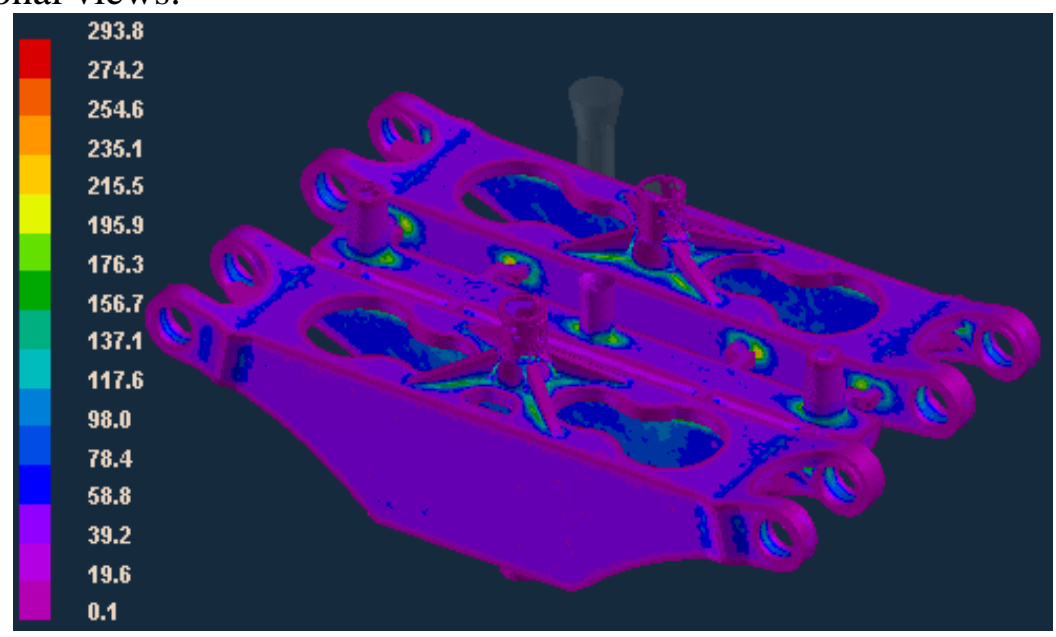

Fig. 10 Different parts’ solidification time

Fig. 9 is the simulation results of optimized process. We can see the distribution of shrinkage is more scattered and sparse compared to the firs improved process. Total possible shrinkage volume measured by software is about $289.15 \mathrm{~cm}^{3}$, the actual shrinkage volume is about $3.15 \mathrm{~cm}^{3}$, the rate of actual shrinkage is $1.09 \%$, and the maximum possible rate of shrinkage is $13.53 \%$. Fig. 10 shows the solidification time at different part of casting, the gap of solidification time at different part is small, it means the solidification of casting meet the principle of meanwhile solidification. It also indicates that this process improvement can achieved a satisfactory result. Table 2 shows the results of three processes. 
Table 2 Simulation results of three processes

\begin{tabular}{lllll}
\hline $\begin{array}{l}\text { Simulation } \\
\text { result }\end{array}$ & $\begin{array}{l}\text { Total possible } \\
\text { shrinkage } \\
\text { volume }\left[\mathrm{cm}^{3}\right]\end{array}$ & $\begin{array}{l}\text { Actual } \\
\text { shrinkage } \\
\left.\text { volume [cm } \mathrm{cm}^{3}\right]\end{array}$ & $\begin{array}{l}\text { Rate of actual } \\
\text { shrinkage [\%] }\end{array}$ & $\begin{array}{l}\text { Maximum } \\
\text { possible rate of } \\
\text { shrinkage[\%] }\end{array}$ \\
\hline $\begin{array}{l}\text { original } \\
\text { process }\end{array}$ & 372.24 & 16.55 & 4.45 & 83.55 \\
$\begin{array}{l}\text { first } \\
\text { improvement }\end{array}$ & 349.39 & 5.01 & 1.43 & 56.18 \\
$\begin{array}{l}\text { second } \\
\text { improvement }\end{array}$ & 289.15 & 3.15 & 1.09 & 13.53 \\
\hline
\end{tabular}

\section{Conclusions}

1) Under the situation of no risers, ingates is very important to the production of steering axle. Reasonable size and number of ingates make ingates to feed the casting well at the time of contraction. When casting is integrally shrinking, ingates can close timely, thereby a less defective product is obtained.

2) Under the technology of Iron mold coated Sand with no riser, gradually increasing the sand thickness from top to bottom of casting, thinning the sand thickness of hot spot, this will be good to the meanwhile solidification of casting. Graphitization expansion can be fully taken advantage of to achieve self-feeding. Reduce or eliminate shrinkage defects

\section{References}

[1] Jianhua Zhao, Gang Song, Jun Tian: Casting • Forging • Welding. Vol. 41 (2012), p. 38. (In Chinese)

[2] Wenqing Wang, Kuisheng Li: Foundry Technology (China Machine Press, Beijing 2002), p. 268-274

[3] Sisheng Cao, Zhibin Zhang: FOUNDRY TECHNOLOGY. Vol. 28 (2007), p. 908. (In Chinese)

[4] Gen Zhou: Modern Cast Iron. Vol. 5 (2004), P. 5. (In Chinese)

[5] Bing Wei, Sen Yuan, Weihua Zhang: Technology of Proportional Solidification and Its Application (China Machine Press, Beijing 1998), p.38-43 